\title{
Reflexões sobre a atual construção curricular das Ciências da Informação: teorias críticas em questão
}

E-mail: moraes.marielle@ gmail.com

Doutoranda pelo Programa de Pós-Graduação em Ciência da Informação, da Escola de Comunicações e Artes da Universidade de São Paulo (PPGCI/ECA) USP).

Mestra em Ciências pelo PPGCI/ECA/USP.

Bacharela em Biblioteconomia pela Universidade Federal do Ceará (UFC).

Bolsista da Fundação de Amparo à Pesquisa do Estado de São Paulo (Fapesp).
Resumo: O currículo dos cursos da área de Ciências da Informação no Brasil está passando por um momento de indefinição, principalmente, a partir da demanda de alterações curriculares feita pelo Ministério da Educação no ano de 2001. Assim sendo, uma questão que ronda essas áreas de conhecimento refere-se a como deve ser construído e desenvolvido o currículo desses cursos. Para tanto, efetuouse uma pesquisa bibliográfica sobre os temas das teorias do currículo e história da Arquivologia, Biblioteconomia, Museologia e Ciência da Informação. As teorizações de Michael Young, Basil Bernstein e Pierre Bourdieu sobressaemse como auxiliares na busca da compreensão dessa questão. Os resultados preliminares vêm apontando para uma perspectiva curricular transdisciplinar, mas sem tornar esta uma indeterminação total.

Palavras-chave: Currículo. Teoria Crítica. Formação de profissionais da informação. 


\section{Introdução}

É inegável a importância da educação para o desenvolvimento das sociedades e para a inserção dos sujeitos nestas. Não é por acaso que as escolas cada vez mais vêm se firmando no centro da vida social desde a Antiguidade, ora como forma de manutenção do status quo, ora como mecanismos de transformação. Assim sendo, as escolas sempre deram uma instrução básica para os sujeitos, no sentido do bem falar e escrever, do desenvolvimento da cultura e, também, para os domínios das técnicas e das tecnologias. Portanto, este tema sempre está presente nas falas mais singelas do cotidiano, às discussões mais complexas dos especialistas nos tempos hodiernos devido à importância cada vez maior da educação nas sociedades, principalmente num momento como o contemporâneo, em que novas literacias estão emergindo com base nas Tecnologias de Informação e de Comunicação (TIC).

Nos albores do século XXI no Brasil, a educação em nível superior, objeto das nossas pesquisas, está se ampliando e também se transformando, principalmente como forma de dar conta das mudanças sociais propiciadas pelas TIC, as quais vêm alterando a cultura das sociedades e, portanto, a própria educação. Com um mundo cada vez mais interconectado, a visão tradicional de ciência e de ensino (as quais são baseadas em pressupostos da primeira modernidade) não mais se sustenta, pois não abarca os problemas suscitados na contemporaneidade devido à natureza de ordem complexa. Portanto, a forma de ciência em que uma teoria poderia explicar determinado fato cede cada vez mais lugar a várias teorias e métodos para explicar um único fato, e isso ocorre tanto no mundo físico quanto no mundo social. No âmbito dos estudos curriculares ocorreu o mesmo, pois o currículo também era teorizado e estruturado no formato da ciência moderna e de uma sociedade cuja industrialização avançava cada vez mais, e este fato influenciou os primeiros teóricos do currículo, no início do século XX, a exemplo de Bobbit ${ }^{1}$ (2004) e Tyler² (1976).

As ideias de Bobbit (2004) vão ao encontro da racionalidade técnico-científica, uma vez que a sua obra The Curriculum, tida como o marco do surgimento do campo do currículo, analisa as finalidades e os processos da educação, bem como a formação para a eficiência profissional e física, para a cidadania, o lazer e para a intercomunicação social. Essa é a abordagem tradicionalista do campo do currículo e que, no Brasil, ainda possui seus resquícios em vários

Originalmente publicada em 1918.

Originalmente publicada em 1949. 
documentos oficiais do campo da educação, em todos os seus níveis, inclusive na educação superior. No entanto, foi a partir dos anos 1960 que surgiram estudos críticos em relação a esta abordagem tradicionalista do campo curricular, a exemplo de Giroux (2004), que afirma que as abordagens críticas tentam direcionar o paradigma tradicional enfocando problemas relacionados com os determinantes sociais, econômicos e políticos da educação.

Mesmo com o desenvolvimento das teorias críticas a partir da década de 1960 (que são aquelas que desconfiam do status quo, responsabilizando-o pelas desigualdades e injustiças sociais, questionam os modelos educacionais vigentes e visam à transformação), ainda nos dias atuais, os documentos oficiais e algumas práticas do cotidiano escolar permanecem atualmente estruturados conforme o paradigma tradicional de currículo. Por mais que a epistemologia contemporânea busque cada vez a reaproximação dos saberes, a educação, em seus mais diversos níveis, continua pautando-se nos modelos de eficácia e eficiência, bem como da disciplinarização, a fim de alcançar altos níveis nos mais diversos rankings educacionais.

Além das questões que envolvem a racionalidade técnico-científica, as quais estão presentes no âmbito da educação, ainda há aquelas relativas à inserção das TIC no interior dos sistemas educacionais como forma de preparar os sujeitos para a atuação naquela que se convencionou denominar de Sociedade da Informação³, a qual está baseada não apenas em informações em formato analógico, mas também naquelas que já nascem no formato digital.

Esta nova sociedade demanda não apenas os conhecimentos herdados do período em que a sociedade operava de maneira analógica, mas passa a demandar também outros tipos de conhecimentos oriundos do mundo digital, o que faz surgir a necessidade de outras literacias, que o mundo operado apenas de forma analógica não demandava, principalmente no que concerne a como operar as sofisticadas máquinas eletrônicas que estão presentes no cotidiano dos sujeitos.

É nesse contexto que se sobressaem as figuras dos profissionais que atuam no campo da mediação de informação e cultura desde os tempos mais imemoriais, tais como arquivistas, bibliotecários e museólogos. Esses profissionais passaram a atuar não somente com informações que estão

A respeito da Sociedade da Informação, Brzezinski (1969 apud MATTELART, 2006, p. 97) afirma que é aquela cuja "forma é determinada pelo plano cultural, psicológico, social e econômico pela influência da tecnologia, mais particularmente, pela informática e pelas comunicações". 
em formato analógico, mas também as que passaram a se apresentar e já nascem no formato digital. Além disso, esses profissionais têm o papel de protagonistas na Sociedade da Informação no que concerne à inserção dos sujeitos nesse novo modelo social.

No que concerne à atuação dos profissionais que atuam no campo da mediação da informação - arquivistas, bibliotecários e museólogos, num ambiente fora de um paradigma custodial (arquivos, bibliotecas e museus) -, fica cada vez mais difícil afirmar qual é o espaço de trabalho de cada um desses profissionais, bem como classificar se são espaços estritamente de arquivistas, bibliotecários ou museólogos.

Os ambientes de mediação da informação contemporâneos, existentes em lugares formais e não formais (tais como o ciberespaço), possuem informações e documentos que já nascem híbridos, impossibilitando, muitas vezes, classificar se é documento de arquivo, biblioteca ou museu, fazendo com que a formação desses profissionais, nos atuais moldes, se torne incompleta. $\mathrm{E}$ é diante de todo esse cenário, muito mais complexo do que o que por ora esboçamos, que surgem as seguintes questões: Qual a contribuição das teorias críticas ao se pensar novos modelos curriculares para a formação dos profissionais da informação? Como deve ser construído e desenvolvido o currículo das Ciências da Informação, ou seja, pautando-se na disciplinaridade do egresso ou abrindo-se aos repertórios e práticas da transdisciplinaridade?

Os objetivos deste estudo são: a) entender a contribuição das teorias críticas para novos modelos curriculares na Ciência da Informação e b) apresentar brevemente a história da Arquivologia, da Biblioteconomia, da Museologia e da Ciência da Informação, a fim de entender a construção curricular dessas áreas de conhecimento.

A metodologia utilizada foi a pesquisa bibliográfica acerca das teorias críticas e da história da Arquivologia, da Biblioteconomia e da Museologia, buscando vislumbrar elementos da história e das teorias críticas que possam contribuir para a construção de um novo currículo nas Ciências da Informação.

Arquivologia, Biblioteconomia e Museologia: Ciência(S) DA Informação?

Na interdisciplinaridade existente entre a Ciência da Informação e as Ciências Sociais existem conceitos e histórias bastante analisados e que passaram a ser tomados como verdade, tais como as narrativas de que a Sociedade da Informação e a Ciência da Informação surgiram devido ao avanço exponencial 
das TIC no seio da sociedade. Inclusive, Le Coadic (1996), Matterlart (2006), Barbrook (2009), dentre outros, demarcam um espaço-tempo específico para o surgimento da Ciência da Informação e da Sociedade da Informação no período do pós-Segunda Guerra Mundial.

No entanto, embora os autores supracitados afirmem que o surgimento da Ciência da Informação (Cl) ocorreu a partir de 1945, bem como da Sociedade da Informação, devido ao desenvolvimento das tecnologias do pós-guerra, seria ingenuidade acreditar que uma área de conhecimento teria data marcada de seu surgimento. Além disso, seria esquecer também que as ciências têm uma historicidade e que não são frutos apenas de um evento, ou de um ou outro autor. A questão principal que Le Coadic (1996) e Matterlart (2006) afirmam ter propiciado o "surgimento" da Ciência da Informação é a explosão informacional surgida com as tecnologias do pós-guerra; todavia, não podemos esquecer que os problemas da explosão informacional também estiveram presentes em outros momentos históricos - basta lembrarmos a Biblioteca de Alexandria e a necessidade que esta teve de organizar seu acervo (sistematizando técnicas de organização) devido ao grande volume informacional já percebido naquele momento.

No entanto, os problemas da explosão informacional não pararam em Alexandria, mas foram se complexificando com o tempo. No século XV, por exemplo, com a invenção da prensa tipográfica por Gutenberg, novos formatos de materiais de informações surgiram, fazendo ocorrer outra explosão informacional. Burke (2003) afirma que, a partir desse período, proliferaram diversos tipos de materiais de informações, tais como: tratados sobre como ser um bom comerciante, informações comerciais sobre feiras de navios, etc. A partir de 1618, jornais holandeses passaram a publicar informações econômicas, incluindo detalhes sobre a chegada de prata do Novo Mundo à Espanha.

Além desses materiais de informações, outros foram surgindo, tais como os panfletos que já eram comuns no século XVI, e a eles se somaram jornais e revistas, que começaram a ser publicados depois de 1600 e, portanto, as notícias já eram vistas como mercadorias no séculoXVII.Com o desenvolvimento de novas tipologias documentárias, incentivadas pelos desenvolvimentos técnicos, surge também a comercialização das informações. Burke (2003) afirma que gazetas de notícias impressas, registradas pela primeira vez na Alemanha em 1609, ganharam impulso na República Holandesa em princípios do século XVII e, no século XVIII, já estavam espalhadas pela Europa. Conhecimentos de tipo acadêmico eram difundidos por revistas 
cultas, publicadas mensalmente ou a cada dois meses. O gênero começara na década de 1660, com o Journal des Savants, em Paris, e as Philosophical Transactions da Royal Society de Londres.

Com todos esses tipos de materiais informativos surgindo, o problema de recuperar a informação apresentou-se mais uma vez e as tradicionais técnicas de recuperação da informação não abarcavam os novos tipos documentários que surgiram. Os livros também proliferaram nesse período, surgindo a necessidade de resenhas de livros no final do século XVII. E às resenhas somaram-se as obras de referência surgidas nesse período, especialmente no século XVIII, tais como enciclopédias, dicionários, atlas e bibliografias. Burke (2003, p. 153) afirma que "a proliferação das obras de referência fora ridicularizada em meados do século XVIII por um homem de letras, Melchior Grimm”, que afirmara que a mania por dicionários era tão aguda que alguém tinha acabado de imprimir um dicionário dos dicionários. E Burke (2003) afirma que ele não exagerara, pois, em 1758, esse Dicionário dos Dicionários foi publicado por Durey de Noinville.

Portanto, do século XVI ao XVIII proliferaram os mais variados materiais de informação, mas, sobretudo, aqueles voltados à investigação científica e técnica, tais como a bibliografia, os dicionários, a elaboração de resumos. Assim sendo, os bibliotecários perceberam que a classificação rudimentar, ou seja, a de livros por assunto, não dava conta das complexidades dos novos materiais de informação, e este fato contribuiu para o surgimento de uma nova área denominada Documentação.

Bradford (1961) afirma que a documentação tem suas origens na Biblioteconomia, quando, em fins do século XV, Johann Tritheim compilou seu Liber de Scriptorium Ecclesiasticis e seu Catalogus Illustrium Virorum Germaniae e, meio século mais tarde, Konrad Gesner preparava sua Bibliotheca Universalis, a primeira tentativa de uma bibliografia universal. Foi nesse período que progrediram as técnicas de organização bibliográfica, quais sejam: Classificação Decimal de Dewey (1876), Rules for a Dictionary Catalogue, compiladas por Charles Ami Cutter, bem como o desenvolvimento da classificação da Biblioteca do Congresso dos Estados Unidos.

Todavia, mesmo com esses sistemas de catalogação e classificação elaborados, havia outro problema a ser enfrentado, a saber, o controle de assuntos da literatura periódica. No entanto, os bibliotecários da época abandonaram esse filão do mercado e este foi desenvolvido pelo crescente grupo dos documentalistas. A área da Documentação emergente nesse período tinha 
um desenvolvimento inseparável da Biblioteconomia, sendo considerada como uma espécie de "evolução" da Biblioteconomia. Resumidamente,

[...] em fins do século XIX, a biblioteconomia e a documentação tinham um

desenvolvimento que era, em grande parte, inseparável. Surgiram em consequência das mesmas necessidades, empregavam processos básicos comuns, tinham objetivos quase idênticos e em muitos casos deviam seu progresso aos mesmos homens. [...]. Em resumo, poder-se-ia dizer que, no início, a documentação, a biblioteconomia e a custódia dos arquivos eram a única e a mesma coisa. Muito cedo, porém, forças sutis começaram a dividir os que se interessavam por essas três atividades em grupos separados, que acabaram por adotar entre si uma atitude de intolerância (BRADFORD, 1961, p. 24-25).

A divergência entre bibliotecários e documentalistas refletiu-se também no que concerne aos órgãos de classe. Em 1908, um grupo de bibliotecários especializados nos Estados Unidos separou-se da American Library Association para formar sua própria associação, a Special Libraries Association. Segundo Rayward (1997) e Bradford (1961), o projeto documentalista teve início no encontro de Paul Otlet e Henry de La Fontaine em 1892 e no reconhecimento de preocupações comuns quanto à organização bibliográfica da produção científica, para o que criaram o Escritório Internacional de Bibliografia, em Bruxelas, na casa de Otlet. Em 1895, promoveram a I Conferência Internacional de Bibliografia, na qual foi aprovada a criação do Instituto Internacional de Bibliografia (IIB), com apoio do governo belga. O IIB teve seu nome alterado para Instituto Internacional de Documentação (IID) em 1938.

Apesar de o desenvolvimento da Documentação ter ocorrido no final do século XIX e início do século XX, em relação aos Estados Unidos, a presença do termo Documentação no nome de associações, de cursos e na literatura deuse apenas nos anos 1950. Nesse período, a Biblioteconomia Especializada dividiu espaço com a Documentação nos Estados Unidos e, logo em seguida, a Documentação passou a ser representada pela Information Retrieval, ou seja, o conjunto de estudos e atividades de armazenamento e recuperação da informação por meio de computadores, e se configura como uma das principais origens da Ciência da Informação nos Estados Unidos nos anos 1960 (ORTEGA, 2009).

Em relação ao Brasil, Ortega (2009, p. 18) afirma que a história da Documentação pode ser identificada em ao menos três momentos: 1) no início do século XX, por envolvimento com o projeto do Instituto Internacional de Bibliografia; 2) a partir de 1940, em movimento que levou à criação do Instituto Brasileiro de Bibliografia e Documentação (IBBD) em 1954 seguindo até a introdução da corrente estadunidense da Ciência da Informação no Brasil e 3) a partir dos anos 1980, com o início dos estudos do Grupo Temma, da Escola de Comunicações e Artes da Universidade de São Paulo. 
O momento posterior à Documentação, seguindo a linha de Ortega (2009), foi o que se passou a denominar Ciência da Informação, a qual Goffman (1970 apud PINHEIRO, 2005), assim como Le Coadic (1996), afirmam ter surgido em consequência dos problemas da explosão informacional do segundo pósguerra, quando foram manipuladas grandes quantidades de informação. Todavia, esta é apenas uma parte da história - há várias versões dela. Outra versão é que a Ciência da Informação teria surgido depois da Segunda Guerra Mundial, com base no artigo de Vannevar Bush (1945), o qual identificou o problema da explosão informacional do pós-guerra e propôs a máquina Memex para solucionar tal problema. Outra narrativa é a visão de Ortega (2004) de que a Ciência da Informação seria uma evolução da Biblioteconomia e da Documentação. Para Borko (1968), foram cinco marcos que possibilitaram o surgimento da Ciência da Informação: 1) o crescimento da ciência e da tecnologia; 2) a rápida obsolescência do conhecimento; 3) o grande número de cientistas em atividade e de periódicos; 4) o aumento da especialização e 5) o pequeno intervalo de tempo entre pesquisa e aplicação, que torna mais imediata a informação.

Além disso, foi nesse período de pós-Segunda Guerra Mundial que foi cunhado o termo Ciência da Informação, em 1955, pelo inglês Jason E. L. Farradane, porém sem a sua definição (WODLEDGE, 1983; SHAPIRO, 1995 apud BENTES PINTO, 2007). No entanto, foi somente na segunda reunião do Georgia Institute of Technology, em 1962, que se elaborou o primeiro conceito de Ciência da Informação, por Taylor (1966), no artigo "Professional aspects of Information Science and Technology", o qual serviu de base para o de Borko (1968), para quem a $\mathrm{Cl}$ é uma ciência interdisciplinar derivada de várias outras e abrange um corpo de conhecimentos que estão relacionados desde a origem até a utilização da informação (PINHEIRO, 2005).

Por outro lado, Ortega (2009) afirma que outra denominação inicialmente utilizada para Ciência da Informação foi Informatologia, como uma tentativa de evitar o termo Documentação, e fora utilizado pela primeira vez em 1962, em uma universidade de Estocolmo, na Suécia. Na realidade, em meio a toda esta discussão acerca da constituição da Biblioteconomia, da Documentação e da Ciência da Informação é que preferimos ficar com a seguinte ideia:

Considera-sequea Biblioteconomia deu origemà Bibliografia, quefundamentou a Documentação, que por sua vez, forneceu insumos à constituição da Ciência da Informação, também denominada de Informatologia. A Ciência da Informação é entendida como a preocupação com a unidade fundamental do 
saber, através de estudos interdisciplinares e de métodos como o estrutural. Engloba o conjunto das disciplinas voltadas para a produção, comunicação e consumo da informação que, chamadas por isso, de ciências da informação, passaram a ser consideradas como uma só ciência da informação. A adoção do termo Ciência da Informação no idioma inglês pode ser verificada já em 1958, com a criação, em Londres, do Institute of Information Scientists, e, dez anos depois, com a mudança de denominação do American Documentation Institute para American Society and Technology, o mesmo ocorrendo com as escolas de Biblioteconomia e publicações (ORTEGA, 2004, p. 10).

Em relação à Arquivologia ${ }^{4}$, esta também surge, assim como a Biblioteconomia, com os primeiros registros humanos. Os palácios e templos possuem locais onde se conservam textos e registros mais variados para serviço das classes dirigentes. A tipologia documental era variada, estando já definidas as principais categorias que integram os arquivos da época mais recente: cartas régias, tratados internacionais, atas, missivas, contratos, assentos contabilísticos, censos, etc. Derivado da noção grega sinônima de santuário, onde se resguardavam os assentos próprios de uma magistratura, o arquivo passa, antes de qualquer coisa, a expressar a ideia de um espaço físico para guardar documentos de valor, devido ao caráter de prova ou memória de fatos. Foi nesse sentido que, durante a Idade Média, o arquivo era chamado de santuário ou tesouro. E é somente na transição da Antiguidade para o Medievo que se firma o conceito e se populariza o termo arquivo (SILVA et al., 2009). Todavia, é importante lembrar que, devido à raridade de alguns textos escritos e dos próprios livros, esses documentos eram guardados num mesmo espaço, independentemente de sua origem ou função.

No campo da Arquivologia, na entrada da modernidade, surgem novas tipologias documentais que os arquivos tiveram de passar a dar conta, devido à evolução do conceito de Administração, passando a conservar os seus documentos muito além da estrita perspectiva jurídica e patrimonial. Conforme Paes (2012), a documentação escrita ou textual se complexificou para inúmeros tipos físicos ou espécies documentais, tais como: contratos, folhas de pagamento, livros de contas, requisições diversas, atas, relatórios, regimentos, regulamentos, editais, certidões, tabelas, questionários, etc. 0 aumento considerável do volume documentário tem consequências imediatas. No século XVI, as rotinas da profissão do arquivista começam a ser disciplinadas por normas regulamentares, as quais irão adquirir a forma Há dúvidas quanto à origem do termo arquivo. 0 mais provável é que tenha surgido na Grécia, com a denominação de arché, atribuída ao palácio dos magistrados. Daí evoluiu para archeion, local de guarda e depósito dos documentos (PAES, 2012). 
de postulados e levar ao surgimento da Arquivística. No entanto, é importante lembrar que a ordenação sistemática, as primeiras etiquetas e os primeiros inventários são oriundos da Antiguidade.

Já no século XVIII, são evidentes os progressos no que concerne à regulamentação em matéria de transferências e de eliminação de documentos. Durante a primeira metade do século XIX, o desenvolvimento do Positivismo, de matriz alemã, preconizando a verificação documental como método a serviço da análise histórica, vem contribuir para que os arquivos adquiram uma posição instrumental relativamente à Paleografia e à Diplomática, disciplinas em ascensão desde os fins do século XVIII (SILVA et al., 2009).

No entanto, mesmo no século XIX, percebemos tentativas de utilizar as técnicas já desenvolvidas da Biblioteconomia no âmbito dos arquivos, o que ocorre até os dias de hoje. Conforme Silva et al. (2009), em 1876 foi desenvolvida a Classificação Decimal de Dewey (CDD), com fins bibliográficos e, para o âmbito do arquivo do Departamento de Estado dos Estados Unidos, foi adotada, em 1910, uma classificação decimal. Na Holanda, em 1908, houve tentativas de introduzir a Classificação Decimal Universal (CDU) nos arquivos municipais.

No que concerne à Museologia, esta tem sua origem também nas primeiras coleções da Antiguidade e o termo "museu" vem do grego mouseion, também usado no período romano como museum, que designava o Templo das Musas - as nove divindades filhas de Zeus, segundo a mitologia grega. À ação humana, simbólica, soma-se a constituição de uma instituição específica, um local físico, um conjunto de procedimentos (ARAÚJO, 2012). Em seguida, o mesmo autor afirma que foi a partir da consolidação da ciência moderna que, durante o século XIX, surgiram diversos manuais que buscaram estabelecer 0 projeto de constituição científica do campo dedicado ao estudo dos museus, mas ainda voltado à vertente da Museografia, ou seja, a de um trabalho técnico de descrição nos museus (MAIRESSE; DESVALLÉS, 2005 apud ARAÚJO, 2012).

Diante deste breve histórico esboçado da Biblioteconomia, Documentação, Ciência da Informação, Arquivologia e Museologia é que podemos afirmar que existe um elo em comum que une essas diferentes áreas de conhecimento que são os processos de mediação informativo-cultural, porque o objetivo precípuo de toda organização documental é a mediação informativo-cultural para os sujeitos. Portanto, a mediação informativo-cultural une todas essas áreas de conhecimento, ou seja, ela é o laço que conecta essas disciplinas, muito embora cada uma delas tenha a sua historicidade, seus métodos e suas técnicas específicas. Conexão não quer dizer integração, mistura total, mas 
sim, que há algo entre elas em comum. Isso não as faz ser uma única ciência, no entanto, são ciências.

Por fim, no momento atual, a Arquivologia, a Biblioteconomia e a Museologia, outra vez, passam por problemas de ter de encontrar alternativas para a nova explosão informacional contemporânea, bem como da diversidade de espécies documentárias, no sentido de que a rede possibilitou a diversificação e a hibridização das informações documentárias. Assim sendo, as tradicionais técnicas desenvolvidas pela Biblioteconomia, Arquivologia e Museologia, isoladamente, não dão mais conta da organização dos documentos do ciberespaço, os quais são novos tipos e que estão cada vez mais hibridizados, mas desta vez encontram-se custodiados em outro ambiente, o ciberespacial, o que configura o paradigma pós-custodial. Dessa forma, vêm à tona mais uma vez as questões relativas à identidade de arquivos, bibliotecas e museus e, nesse ínterim, da formação de arquivistas, bibliotecários e museólogos e os respectivos currículos dessas áreas de conhecimento.

\section{Currículo, teorias críticas e formação em Ciência da Informação5}

O currículo é um artefato social e cultural que legitima e autoriza qual parte da cultura deve ser mediada para os sujeitos da educação, daí a relação intrínseca entre escola e cultura e entre currículo e cultura. Muito embora haja diversas conceitualizações para o termo currículo, o que daria uma discussão muito mais alongada para os objetivos deste artigo, para este momento ressaltamos que as várias definições vão depender da perspectiva de cada estudioso dessa área, bem como das teorias às quais esses estudiosos estão mais voltados. A esse respeito, é desta maneira que se expressa Barreto (2006, p. 2):

É possível encontrar inúmeras definições de currículo, pois elas têm variado no tempo e no espaço. Algumas definições tendem a enfatizar o conjunto de experiências adquiridas pelo aluno na escola. Outras recaem nos conteúdos e disciplinas a serem trabalhados com os estudantes com vistas a determinados objetivos. 0 que o currículo é, depende da forma como ele é definido pelos autores e pelas teorias que dele se ocupam. A abordagem do currículo precisa, portanto, ser feita de uma perspectiva histórica.

Também foram discutidas as teorias críticas em sua relação com a construção curricular da Arquivologia, da Biblioteconomia e da Museologia em trabalho desenvolvido por Moraes e Sánchez Espinoza (2014), o qual é complementar a este. 
Assim sendo, a escola, no início do século XX, passou a ser vista como um espaço privilegiado, capaz de adaptar as novas gerações para as transformações sociais, culturais e econômicas que estavam ocorrendo diante da crescente industrialização advinda com o pós-guerra. Portanto, para dar conta de "pôr na forma" os alunos, era necessário criar processos racionais e eficientes de escolarização, e o espaço privilegiado para efetivar essa ideia era o do currículo escolar.

A elaboração dos currículos com base nos objetivos e na eficiência permaneceu no âmbito das escolas durante toda a primeira metade do século XX. Em alguns países, continuou com bastante ênfase até idos dos anos 1980 e, em outros lugares, ainda é modelo para a elaboração curricular. Todavia, mesmo cônscios dessa continuidade, no âmbito deste trabalho, baseamonos nas teorias críticas como forma de buscar uma nova práxis curricular para a formação dos profissionais da informação (arquivistas, bibliotecários e museólogos).

Sim, falamos aqui que as teorias críticas contribuiriam para uma nova práxis desses profissionais, no sentido da ampliação dos espaços de trabalho, uma vez que a partir do novo formato do currículo para as áreas de conhecimento em pauta, haverá mais espaço para a criação e recriação dos espaços de trabalho para muito além dos mercados já estabelecidos. Se atentarmos para a historicidade dos currículos de Biblioteconomia especificamente, perceberemos que essa área vem formando profissionais desde o início do século XX no Brasil e, portanto, coincide com o surgimento das teorias tradicionais de currículo. Desta feita, os currículos dessa área receberam muita influência dessas teorias, inclusive nos tempos contemporâneos, sendo que o mesmo ocorre com os currículos da Arquivologia e da Museologia.

Autores como Basil Bernstein, Pierre Bourdieu, Michael Apple, Henry Giroux e Michael Young trazem conceitos e proposições que podem nos auxiliar numa maior compreensão em busca de outra formação dos profissionais da informação nos tempos modernos. No entanto, para o escopo deste artigo, abordamos as teorias de Bourdieu (2012, 2004), Young (2011) e Bernstein (1988), relacionando suas teorias à Ciência da Informação.

Young (2011) trata do enfraquecimento das fronteiras disciplinares e relaciona esse fato com o que vem ocorrendo com os Estados Nacionais através do fenômeno da globalização. Sendo assim, para o autor, disciplinas são conjuntos de conceitos teóricos inter-relacionados e também uma forma de organização social que permite que os especialistas estejam reunidos 
em torno de disciplinas, conferindo-lhes suas identidades. Portanto, as disciplinas possuem histórias e tradições distintas umas das outras.

Muito embora Young (2011) perceba a importância das disciplinas na sociedade do conhecimento, o autor enfatiza a distinção de um currículo centrado em disciplinas por acatamento e um currículo centrado em disciplinas por engajamento. Young afirma que o currículo por acatamento possui disciplinas que são vistas como parte de um cânone fixo definido pela tradição, com conteúdos e métodos imutáveis. Se relacionarmos aos currículos dos cursos de Arquivologia, Biblioteconomia e Museologia conforme estão delineados no Brasil, podemos afirmar que as disciplinas estão inseridas nesses currículos “por acatamento". O motivo é que, devido à sua história de desenvolvimento curricular, o qual é oriundo de um paradigma da ciência moderna, definiuse que alguns conhecimentos, por mais que sejam semelhantes no âmbito das três áreas, mesmo assim estariam em currículos separados para formar esses três profissionais. Ou seja, mesmo que esses três currículos abordem a criação, organização, mediação e uso dos materiais de informação para os sujeitos, ainda assim, as formações estão separadas e esse fato é justificado pelo paradigma custodial. Portanto, a formatação dos currículos baseada na separação disciplinar entre Arquivologia, Biblioteconomia e Museologia é tomada pelos elaboradores de currículo como se fossem separações naturais e instrucionais.

Já no currículo por engajamento ressalta-se que as disciplinas possuem uma historicidade, mudam com o tempo, principalmente devido ao desenvolvimento das ciências, por pressões políticas e outras pressões. Na verdade, nesse tipo de currículo, as disciplinas não são vistas como verdades inquestionáveis. Elas podem se articular, todavia, respeitando-se as diferentes histórias, tradições e modos de trabalhar. E é aqui que encontramos o pensamento de Young (2011) revisitado por ele mesmo, a partir do momento em que ele afirma que as disciplinas são importantes no que concerne à inserção dos sujeitos na sociedade do conhecimento. Assim sendo, as disciplinas têm papel importante no que se refere ao acesso dos estudantes ao conhecimento mais confiável; à ponte para que os aprendizes passem dos conceitos do cotidiano aos conceitos teóricos; e também conferem identidade aos professores e aos aprendizes.

Já o teórico Bernstein (1988) e seus conceitos de classificação forte e classificação fraca nos possibilita uma maior compreensão acerca dos currículos da área. Podemos perceber que, no campo epistemológico, as 
"três marias", conforme são denominadas por Smit (2002) a Arquivologia, a Biblioteconomia e a Museologia, possuem uma classificação fraca, ou seja, possuem um baixo nível de isolamento entre esses domínios do conhecimento, principalmente no que se refere às práticas de mediação da informação, as quais, embora não delineadas, são tidas como o ato de elaborar estratégias para que os sujeitos consigam sentir necessidade, saibam encontrar, usar e reusar a informação tendo em vista a transformação desse sujeito. Essa classificação fraca se reflete também no caso das tipologias documentárias mais contemporâneas que já nascem em formato de fluxos na rede, uma vez que é difícil classificar se elas são objeto de trabalho de arquivistas, bibliotecários ou museólogos.

Embora os discursos dos professores dos campos da Arquivologia e da Museologia sejam fortemente classificados, a Biblioteconomia, por ser muitas vezes confundida com a Ciência da Informação, não possui uma classificação forte, podendo muitas vezes se confundir com outros campos de conhecimento, tais como a Gestão da Informação. Portanto, o que define Biblioteconomia vai depender de sua relação com a Arquivologia e a Museologia, como cita Bourdieu (2012) quando se refere ao conceito de lutas e campos. Assim, seguindo as ideias de Bernstein (1988) e relacionando ao campo das Ciências da Informação, a Biblioteconomia tem a voz da Arquivologia e da Museologia, mas não possui a mensagem de cada disciplina e este fato é percebido, principalmente, nos currículos de formação desses profissionais.

Quando a Arquivologia, a Biblioteconomia e a Museologia se apresentam fortemente enquadradas, os alunos e os professores têm pouca iniciativa, os conteúdos e os métodos de ensino estão fortemente prescritos. Daí o conhecimento e a cultura serem vistos a partir de uma perspectiva dogmática.

Outro autor, cujas ideias contribuem bastante para repensar os currículos dos cursos da Ciência da Informação, é Bourdieu (2012). Ele nos faz compreender que há campos que são censurados devido a uma hierarquia - nos campos de produção simbólica - dos objetos em legítimos, legitimáveis ou indignos. Esse fato pode ser visualizado na nomenclatura do próprio curso de graduação em Biblioteconomia, pois, nos últimos anos, como forma de superar um estereótipo da área, o qual a torna um campo quase desconhecido na sociedade, muitos cursos passaram a se denominar ciência ou de gestão da informação - como na Universidade Federal de Goiás, Universidade Federal de Pernambuco, Universidade Federal do Paraná, dentre outros -, por mais que os conteúdos curriculares desses cursos possuíssem disciplinas semelhantes 
aos currículos dos cursos que se denominam Biblioteconomia. Esse fato pode ser corroborado com a afirmação de um teórico que há muitos anos se dedica ao estudo da educação em Biblioteconomia, a saber, Souza (2007, p. 63):

É por essa via que, nos anos recentes, surgiram projetos ou cursos de graduação, no Brasil, com a designação Ciência ou Gestão da Informação. Neste caso, são propostas curriculares e projetos pedagógicos que competem diretamente com os cursos de Biblioteconomia e Arquivologia já estabelecidos, sobretudo, pelo apelo representado por uma carga de horasaula maior em informática e gestão. No entanto, não trazem novidade teórica ou epistemológica. [...] ou seja, exceto pela propalada inserção das recentes tecnologias de informação, não difere, epistemologicamente, dos cursos de Biblioteconomia ou Arquivologia ofertados nas últimas décadas.

Quando falamos em refazer o diálogo no âmbito dos currículos dos cursos de Arquivologia, Biblioteconomia e Museologia, temos em mente que, se num primeiro momento os conhecimentos que hoje estão contidos pelos cursos de Arquivologia e de Museologia estavam contidos nos currículos de Biblioteconomia, então há a possibilidade desse restabelecimento de laços.

No entanto, sabemos que as áreas científicas possuem uma história, uma tradição e o seu desenvolvimento se perpetua, conforme afirma Bourdieu (2004), como uma espécie de partenogênese. E então, o próprio autor vem afirmar que é necessário que as ciências saiam desse purismo, no sentido de ser livres de qualquer necessidade social, e também deixem de lado a servidão, deixem de se portar como ciências escravas e sujeitas a todas as demandas político-econômicas, até mesmo porque o mundo científico funciona como o mundo social e, por isso, independente das pressões desse mundo social, porque tem as suas próprias pressões. $E$, com base na forma como as ciências funcionam, ou seja, semelhante ao mundo social, Bourdieu (2004) elaborou a noção de campo.

Para Bourdieu (2004), campo é um espaço relativamente autônomo, um microcosmo dotado de leis próprias. Os agentes sociais desse campo possuem disposições, habitus - isto é, maneiras de ser permanentes, duráveis, que podem, em particular, levá-los a resistir, a opor-se às forças do campo. Nesse sentido, a Arquivologia, a Biblioteconomia e a Museologia são campos científicos, haja vista que possuem leis próprias e que são permanentes, duráveis, e que também se transformam com o tempo. Por mais que as forças do campo estejam voltadas para a abertura ao diálogo entre essas três áreas no campo epistemológico, e para uma abertura como forma de sair desse 
purismo epistemológico e curricular, ainda assim, há receio de que esse diálogo propicie a perda da autonomia desses campos e formem apenas um único campo hegemônico. E então, é aqui que retomamos o diálogo com Young (2011), que, a partir da revisitação de seu próprio pensamento, volta atrás e se posiciona afirmando acerca da importância das disciplinas na sociedade do conhecimento.

Assim, com base nas perspectivas de Bernstein (1988), Bourdieu (2012, 2004) e Young (2011), podemos vislumbrar alguns novos modelos para a formação dos profissionais da informação, voltando-se para a perspectiva do transdisciplinar, do complexo. Portanto, para que essa nova perspectiva curricular se efetive, os atores dos campos científicos também precisam mudar de postura. De uma postura de celebração pura e simples da tradição dos campos de conhecimento e de estruturação curricular, a qual é voltada para o paradigma de uma disciplinaridade curricular, para voltar-se, dialeticamente, para a modernidade das formas curriculares, a qual visa à reaproximação dos saberes no campo epistemológico e, também, curricular.

\section{Considerações finais}

As discussões que este trabalho buscou despertar incluem as possíveis contribuições das teorias críticas, especificamente as de Young, Bernstein e Bourdieu, para um novo currículo dos cursos que compõem a Ciência da Informação no Brasil, principalmente no que concerne à importância das disciplinas nos currículos de nível superior. Por mais que percebamos a importância da disciplinarização como forma de conferir uma identidade a esse sujeito, ainda assim é importante a abertura desse currículo à transdisciplinaridade, para dar conta das demandas da sociedade, que são cada vez mais complexas.

Pierre Bourdieu, Michael Young e Basil Bernstein apresentam conceitos importantes para repensar a formação nessas áreas de conhecimento. Esses conceitos nos fazem perceber os processos pelos quais vêm passando a Arquivologia, a Biblioteconomia e a Museologia na contemporaneidade, principalmente a partir do maior desenvolvimento do que se convencionou denominar Ciência da Informação. Do lado de Bernstein, os conceitos de classificação forte e classificação fraca possibilita-nos perceber que deixa cada vez mais de fazer sentido um currículo separado para essas três áreas de conhecimento, à medida que se torna cada vez mais difícil delimitar onde começam e onde terminam as especificidades de cada uma 
das três áreas analisadas, principalmente quando se levam em conta as hibridizações documentárias e os ambientes de medição informativo-culturais contemporâneos.

No que concerne às ideias de Young, os conceitos de currículo por engajamento e currículo por acatamento faz-nos refletir sobre a tradição formativa na Arquivologia, na Biblioteconomia e na Museologia. Ou seja, esses currículos no Brasil, devido ao seu desenvolvimento histórico, são baseados no paradigma da disciplinaridade da formação, por mais que dialoguem de forma interdisciplinar. Na realidade, até hoje, a conformação dos currículos das Ciências da Informação é por acatamento, ou seja, sua elaboração é vista como uma verdade inquestionável. No entanto, assim como Young, percebemos também a importância das disciplinas como forma de os sujeitos se posicionarem num determinado campo científico, conceito bastante caro para Bourdieu.

Já em relação a Bourdieu, há diversos conceitos importantes para se repensar a formação na Ciência da Informação, principalmente os conceitos de objetos legítimos, legitimáveis e indignos, bem como o conceito de campo (pouco explorado neste artigo). Esses conceitos nos fizeram perceber que há mediações entre os campos científicos que os tornam legítimos, legitimáveis e indignos, e que essas classificações não são duradouras para os campos científicos.

Podemos perceber esse fato no campo da Biblioteconomia, por exemplo, a qual era um objeto legítimo (quem ingressava nesse curso era a elite pensante do início do século XX no Brasil), em seguida passou a ser objeto indigno (já que os alunos passaram a ingressar nesse curso devido à baixa concorrência do vestibular e os que nele ingressavam vinham geralmente das classes menos favorecidas da sociedade) e, neste momento, é um objeto legitimável, principalmente com o advento da Ciência da Informação, em que esses dois campos de conhecimento, muitas vezes, se confundem como práxis e também no campo curricular. No entanto, esta questão é bem complexa e demanda discussões mais aprofundadas.

O que é importante na teoria de Bourdieu para este estudo, especificamente, é a sua ideia de que não tem mais como as ciências atuarem de forma purista, buscando o seu desenvolvimento per si e deixando de lado as necessidades sociais. Mas também não tem como as ciências buscarem as suas transformações conforme as demandas alucinantes do mercado. $\mathrm{Na}$ realidade, as ciências têm as suas próprias pressões e, no momento 
contemporâneo, uma das pressões do próprio campo da Ciência da Informação é a busca de uma atuação mais complexa, mais transdisciplinar e não apenas no que concerne ao fazer científico, como apontam as pesquisas de Araújo (2011), mas também no que se refere à sua construção curricular e atuação profissional.

Desta feita, as teorias críticas são elementos importantes para se repensar a formação na Arquivologia, na Biblioteconomia e na Museologia, mas também, e, num mesmo grau de importância, a historicidade e a epistemologia dessas áreas de conhecimento como forma de entender a atual formação nessas áreas. 


\section{Reflections on current Information Sciences curriculum building: critical theories at issue}

Abstract: The curriculum of Information Science in Brazil is going through a time of uncertainty, mainly from the demand curriculum changes made by the Ministry of Education in 2001. Therefore this is a question round these areas of knowledge is how it should be built and developed the curriculum of Information Sciences. To do so, we performed a Literature Search on the topics of curriculum theories and history of Archival, Library Science, Information Science, and Museology. Theorizations Michael Young, Basil Bernstein and Pierre Bourdieu excel as aids in the search for understanding of this issue. Preliminary results have pointed to a transdisciplinary curricular perspective, but without making this a complete indeterminacy.

Keywords: Curriculum. Critical Theory. Training of information professional. 


\section{REFERÊNCIAS}

ARAÚJO, Carlos Alberto Ávila. Condições teóricas para a integração epistemológica da Arquivologia, Biblioteconomia e Museologia na Ciência da Informação. InCID: R. Ci. Inf. e Doc., Ribeirão Preto, v. 2, n. 2, p. 19-41, jul./dez. 2011. Disponível em: 〈www.revistas.usp.br/incid/article/view/42349/46020〉. Acesso em: 10 nov. 2012.

- Museologia: correntes teóricas e consolidação científica. Revista Museologia e Patrimônio, Rio de Janeiro, v. 5, n. 2, p. 31-54, 2012. Disponível em: 〈revistamuseologiaepatrimonio.mast.br/index.php/ppgpmus/ article/.../199>. Acesso em: 20 maio 2014.

BARBROOK, Richard. Futuros imaginários: das máquinas pensantes à aldeia global. São Paulo: Peirópolis, 2009.

BARRETO, Elba Siqueira Sá de. Tendências recentes do currículo da escola básica. Difusão de Ideias, São Paulo, p. 1-13, dez. 2006. Disponível em: 〈http://www.fcc.org.br/conteudosespeciais/difusaoideias/pdf/congresso_ tendencias_recentes.pdf $\rangle$. Acesso em: 10 maio 2012.

BENTES PINTO, Virgínia. Interdisciplinaridade na Ciência da Informação: aplicabilidade sobre a representação indexal. In: BENTES PINTO, Virgínia; CAVALCANTE, Lídia Eugênia; SILVA NETO, Casemiro. Ciência da Informação: abordagens transdisciplinares, gêneses e aplicações. Fortaleza: UFC, 2007, p. 105-142.

BERNSTEIN, Basil. Poder, control, principios de comunicación. In: BERNSTEIN, Basil. Poder, educación y consciência: sociologia de la transmisión cultural. Santiago: CIDE, 1988, p. 19-37.

BOBBITT, John Franklin. 0 currículo. Trad. J. M. Paraskeva. Lisboa: Didáctica, 2004.

BORKO, Harold. Information Science: what is it? American Documentation, v. 19, n. 1, p. 3-5, jan. 1968. Disponível em: «www.marilia.unesp.br/Home/.../k--artigo-01.pdf $\rangle$. Acesso em: 20 maio 2013.

BOURDIEU, Pierre. Método científico e hierarquia social dos objetos. In: BOURDIEU, Pierre. Escritos de educação. Trad. Maria Alice Nogueira e Afrânio Catani. 13. ed. Petrópolis: Vozes, 2012.

Os usos sociais da ciência: por uma sociologia clínica do campo 
científico. Trad. Denice Barbara Catani. São Paulo: Editora Unesp, 2004.

BRADFORD, S. C. Documentação. Trad. M. E. de Mello Cunha. Rio de Janeiro: Fundo de Cultura, 1961.

BURKE, Peter. A classificação do conhecimento: currículos, bibliotecas e enciclopédias. In: . Uma história social do conhecimento: de Gutenberg a Diderot. Rio de Janeiro: Jorge Zahar, 2003, p. 78-108.

BUSH, Vannevar. As we may think. Atlantic Monthly, Boston, v. 176, n. 1, p. 101-108, 1945.

GIROUX, Henry. Teoría y resistencia en educación: una pedagogia para la oposición. 6. ed. Ciudad de México: Siglo XXI Editores, 2004.

LE COADIC, Yves-François. A ciência da informação. Trad. Maria Yeda F. S. de Figueiredo Gomes. Brasília: Briquet de Lemos, 1996.

MATTELART, Armand. História da sociedade da informação. Trad. Nicolas Nyimi Campanário. São Paulo: Loyola, 2006.

MORAES, Marielle Barros de; SÁNCHEZ ESPINOZA, Ariel. Teorias críticas de currículo: contribuições preliminares para repensar a formação nas ciências da informação. In: INTERNATIONAL CONFERENCE ON INFORMATION SYSTEMS AND TECHNOLOGY MANAGEMENT, 11., 2014, São Paulo. Proceedings of the 11th CONTECSI... São Paulo: TECSI, EAC, FEA, USP, 2014. V. 1, p. 3730-4260. Disponível em: <file:///C:/Users/Marielle\%20de\%20Moraes/Downloads/8342655-1-PB.pdf>. Acesso em: 10 jul. 2014.

ORTEGA, Cristina Dotta. Relações históricas entre Biblioteconomia, Documentação e Ciência da Informação. Datagramazero: Revista de Ciência da Informação, v. 5, n. 5, 2004. Disponível em: 〈www.dgz.org.br/out04/ Art_03.htm>. Acesso em: 20 nov. 2013.

. Surgimento e consolidação da Documentação: subsídios para a compreensão da história da Ciência da Informação no Brasil. Perspectiva em Ciência da Informação, Belo Horizonte, v. 14, n. esp., p. 59-79, 2009. Disponível em: 〈www.scielo.br/pdf/pci/v14nspe/a05v14nspe.pdf〉. Acesso em: 10 jun. 2012.

PAES, Marilena Leite. Arquivo: teoria e prática. 3. ed. Rio de Janeiro: FGV, 2012. PINHEIRO, Lena Vânia Ribeiro. Processo evolutivo e tendências contemporâneas 
da Ciência da Informação. Informação e Sociedade: Estudos, João Pessoa, v. 15, n. 1, p. 13-48, jan./jun. 2005. Disponível em: 〈www.ies.ufpb.br/ojs/index. php/ies/article/viewFile/51/1521 . Acesso em: 20 abr. 2014.

RAYWARD, W. B. The origins of the Information Science and the International Institute of Bibliography/International Federation for Information and Documentation (FID). Journal of the American Society for Information Science, Maryland, v. 48, n. 4, p. 289-300, 1997.

SILVA, Armando Malheiro et al. Arquivística: teoria e prática de uma ciência da informação. 3. ed. Porto: Afrontamento, 2009. v. 1.

SMIT, Johanna Wilhelmina Arquivologia, Biblioteconomia e Museologia: o que agrega estas atividades profissionais e o que as separa? Revista Brasileira de Biblioteconomia e Documentação, São Paulo, v. 1, n. 2, p. 27-36, fev. 2002.

SOUZA, Francisco das Chagas de. Interdisciplinaridade da Ciência da Informação. In: BENTES PINTO, Virgínia; CAVALCANTE, Lídia Eugênia; SILVA NETO, Casemiro. Ciência da Informação: abordagens transdisciplinares, gêneses e aplicações. Fortaleza: UFC, 2007, p. 49-70.

TAYLOR, Robert S. Professional aspects of Information Science and Technology. Annual Review of Information Science and Technology (ARIST), Maryland, v. 1, p. 15-40, 1966.

TYLER, Ralph W. Princípios básicos de currículo e ensino. Trad. Leonel Vallandro. 3. ed. Porto Alegre: Globo, 1976.

YOUNG, Michael. O futuro da educação em uma sociedade do conhecimento: o argumento radical em defesa de um currículo centrado em disciplinas. Revista Brasileira de Educação, v. 16, n. 48, p. 609-810, 2011.

RECEBIDO: Maio de 2014.

APROVADO: Julho de 2014. 